DOI:

\title{
TRABALHADORES À DERIVA NA EMPRESA FRAGMENTADA DO SÉCULO XXI: FUNDAMENTOS PARA UMA POLÍTICA EMANCIPATÓRIA
}

\author{
ADRIFT WORKERS IN THE FRAGMENTED XXI CENTURY \\ COMPANY: FUNDAMENTALS TO AN EMANCIPATORY POLICY
}

DANIEL AMIN FERRAZ

Doutor em Direito Internacional pela Universidad de València, Espanha. Mestre em Direito Empresarial pela Universidade de Coimbra, Portugal. Pesquisador Convidado da OMC, Genebra, Suíça; Professor do Mestrado/Doutorado em Direito do UniCEUB; Coordenador do DEMP - Grupo de pesquisa em Direito Empresarial, UniCEUB; Advogado; E-mail daniel.amin@afcadvogados.adv.br.

\section{GERARDO ALVES LIMA FILHO}

Mestre em Direito e Políticas Públicas pelo UniCEUB, Brasília, DF. Doutorando em Direito Econômico pela UnB, Brasília, DF. Professor Universitário; membro do DEMP - Grupo de pesquisa em Direito Empresarial; Oficial de Justiça, presidente do SINDOJUS-DF; E-mail: gerardoalveslimafilho@gmail.com

\section{RESUMO}

Este artigo trata das transformações e suas principais consequências do mundo empresarial e do trabalho no século XXI. Nesse sentido, inicialmente busca identificar as principais tendências e características dessa possível nova fase de interação dos agentes econômicos, tentando ainda investigar os riscos decorrentes para o grupo vulnerável dos trabalhadores. Em seguida, examina esse conjunto de alterações no plano legislativo nacional, analisando a sua compatibilidade ou não com o sistema de proteção social da Constituição Federal de 1988. Posteriormente, aplica a teoria da integridade de Ronald Dworkin a fim de verificar se as alterações estão de acordo com 
DOI:

os princípios da igual consideração e respeito para com todos os cidadãos e da autonomia de cada um fazer as escolhas acerca da sua própria vida. Por fim, apresenta sugestões no sentido de garantir um modelo que promova a emancipação do trabalhador, como sujeito que oferece para a sociedade suas potencialidades enquanto manifestação da sua dignidade no mundo do trabalho.

PALAVRAS-CHAVE: Alterações empresariais e trabalhistas; Reformas Inconstitucionais; Teoria da Integridade.

\section{ABSTRACT}

This article deals with the transformations and main consequences of the XXI century business and labor worlds. In this sense, it initially tries to identify the main tendencies and characteristics of this possible new interaction phase of the economic players and trying to explore the risks resulting to the vulnerable group of the workers. Then, this set of changes is examined at the legislative level, analyzing its compatibility or incompatibility with the social protection system of the 1988 Federal Constitution. Later, Ronald Dworkin's integrity theory is applied to verify if the alterations are accord to the principles of equal consideration and respect to all citizens, and the autonomy of each citizen to choose the aspects of their own life. Last, suggestions are made to ensure a model that promotes the worker's emancipation as a subject that offers its potentialities to society as a manifestation of their dignity in the labor world.

KEYWORDS: Business and labor changes; Unconstitutional Reforms; Theory of Integrity.

\section{INTRODUÇÃO}

O objeto de pesquisa do presente artigo apresenta-se com relevância econômica e social, vez que procura oferecer luzes para a compreensão das transformações empresariais atuais. Ademais, o aprofundamento da temática possui 
DOI:

importância vital na definição de eventual regulação aplicável para os novos arranjos contratuais $^{1}$, bem como no regime de responsabilidade ${ }^{2}$, mormente no que diz respeito a agentes vulneráveis, como é o caso do trabalhador e do consumidor ${ }^{3}$, e a direitos difusos, existentes em ramos como o Direito Concorrencial e Ambiental (FRAZÃO, 2015, p. 208).

Com efeito, nos últimos anos, intensificou-se processo de exaurimento [hollowing-out] da grande empresa e o predomínio de fenômenos de desverticalização, terceirização [outsourcing], redes interempresariais [networks] e desagregação na atividade produtiva. Nesse contexto, as ferramentas próprias do mercado passaram a prevalecer em relação às estruturas burocráticas empresariais (AMATORI; COLLI, 2011, p. 317-318 e 458).

Exemplo emblemático do processo de desintegração empresarial, a explosão da contratualização do processo produtivo ensejou a dissolução das fronteiras e rompeu a demarcação vertical entre empresas. Surgem, nesse contexto, diversas alianças externas e formas distintas de governança contratual (ARAUJO, 2007, p. 244-245).

A alteração mais relevante nesse processo de transformação consiste na mudança das burocracias verticais para a empresa horizontal. Sete tendências são apontadas nesse novo modelo: 1) organização pautada no processo e não na tarefa; 2) hierarquia de natureza horizontal; 3) gerenciamento com base na equipe; 4) aferição do desempenho a partir da satisfação da clientela; 5) recompensas oferecidas para a equipe em função do desempenho; 6) maior aproximação com fornecedores e clientes; e 7) elevação da informação e do treinamento de todos os funcionários (CASTELLS, 1999, p. 184-185).

\footnotetext{
1 Para aprofundamento com respeito às novas categorias de acordos praticados entre os empresários coletivos, que poderiam gerar não só instrumentos de concentração empresarial, como também de cooperação interempresarial, veja-se, dentre muitos: FERRAZ, 2012a, p. 149-160. Sobre a tipologia dos contratos de Joint Venture, como nova forma de organização empresarial: FERRAZ, 2001, p. 102 e ss.

2 Para análise do critério objetivo de desconsideração, com extensão de responsabilidade, veja-se: FERRAZ; SÁ, 2016a, p. 120-139.

3 Para análise da ampliação da responsabilidade no âmbito da relação de consumo, decorrente da existência de novas formas de organização da empresa plurissocietária, veja-se: FERRAZ; SÁ, 2016b, p. 306-317.
} 
DOI:

Em síntese, as redes contratuais dizem respeito a um feixe de relações negociais entre agentes econômicos funcionalmente interligadas, estabelecendo entre si alto grau de conexão. Nesse cenário, as redes contratuais também operam no sentido de estabelecer novas formas de alocação de risco e responsabilidade entre os empresários, bem como de fixar novas maneiras de coordenação entre os agentes, não mais pautada na hierarquia (FRAZÃO, 2017a).

A esse respeito, faz-se mister salientar que as redes interempresariais desafiam os juristas como uma nova forma de atuação de "empresas"4 com direção única. A grande preocupação com esse formato se refere à possibilidade de ensejar a "irresponsabilidade organizada". Com isso, os arranjos contratuais caracterizados como empresas devem atrair a aplicação dos ramos de regulação dura [Direito do Trabalho e Direito do Consumidor, por exemplo], com incidência do princípio da primazia da realidade e adequada distribuição do poder e da responsabilidade (FRAZÃO, 2017b).

Fenômenos recentes dessas transformações, os modelos de negócios relacionados com a economia do compartilhamento e as tecnologias disruptivas ${ }^{5}$, outrossim, têm sido utilizados amiúde com o desiderato de afastar a regulação jurídica existente. Nesses casos, verifica-se que em diversas situações se aplica um modelo

\footnotetext{
${ }^{4}$ Para o direito societário clássico, haveria uma clara distinção entre empresa e empresário. Aquela seria qualificada como objeto de direito mercantil, por isso mesmo passível de negociação no mercado, de forma autônoma e independente. Por seu turno, este, o empresário, teria natureza jurídica de sujeito de direito e não de objeto sendo, por isso mesmo, o agente que assumiria deveres e adquirira direitos. Claro está que essa conceituação clássica não é suficiente para a solução dos problemas que hoje se apresentam ao trabalhador, com estas novas formas de organização da atividade empresária (empresa de grupo). Assim, para o presente artigo entenda-se as expressões empresa e empresário como sinônimas. Veja-se, sobre a distinção entre empresa e empresário: FERRAZ, 2015, p. 449 e ss. Para uma análise das concepções subjetivista (que qualifica a empresa como sujeito de direito) e patrimonialista (que qualifica a empresa como objeto de direito), veja-se: FONT GALÁN, 2010, p. 61 e ss.

${ }^{5} \mathrm{~A}$ Internet gera, na sociedade atual, profundas transformações, nos mais diversos aspectos. Entre eles, promove a profunda modificação da forma de atuação dos agentes econômicos, em especial o setor financeiro. No Brasil, a concessão de crédito é uma atividade exercida por instituições financeiras, sob a fiscalização do Conselho Monetário Nacional e do Banco Central. Por outro lado, existiriam atividades, até então de cunho bancário, que seriam desempenhadas por agentes não bancários, que atuam de forma semelhante aos bancos comerciais e permitem que eles transfiram os riscos do crédito. Veja-se, neste sentido: veja-se: RIZZARDO, 2007, p.91 e ss. Essas novas modalidades de exercício bancário e financeiro, que serão desenvolvidas também por agentes não bancários, são exercidas tanto em espaços físicos definidos, como também, de forma crescente, mediante a alocação no universo digital. Este é o contexto da desbancarização, que amplia a atuação de entidades não bancárias no mundo digital, com trocas digitais e financiamento e investimento em atividades em rede, com a utilização do bitcoin. Veja-se: BARBIER, 2007, p. 9 e ss.
} 
DOI:

fundado em interações econômicas protagonizadas por um agente empresarial, que possui o controle do conteúdo dos negócios jurídicos celebrados entre as duas pontas da rede. A esse respeito, uma provocação inicial já se apresenta no sentido de apurar se a principal vantagem desses novos modelos de negócio diz respeito à capacidade de se furtar à aplicação de normas de regulação dura, como o Direito do Trabalho e o Direito do Consumidor. Sob essa ótica, mostra-se de grande relevância, conforme mencionado acima, a aplicação do princípio da primazia da realidade sobre a forma dos negócios, bem como a adequada distribuição entre poder e responsabilidade empresarial (FRAZÃO, 2017c).

Ao longo da história, percebe-se a ocorrência de profundas transformações no sistema legal de imputação de riscos e responsabilidades pelo exercício da atividade empresarial. Os formatos jurídicos adotados no decorrer do tempo foram a empresa individual [explorada pelo empresário individual], a empresa social [exercida pela sociedade empresária] e a empresa de grupo [explorada por um conjunto de sociedades empresárias dotado de comando unitário] (ANTUNES, 2005, p. 30). Hodiernamente, vislumbra-se a transição para uma quarta fase, pautada pela desfragmentação empresarial e pela estipulação de poder de controle por meio de vínculos contratuais não societários ${ }^{6}$.

Nesse contexto, também o mundo do trabalho experimenta um complexo de transformações, com processos de fragmentação e reconstrução que demandam dos juristas respostas aptas a manter um sistema de proteção aos trabalhadores nos novos formatos empresariais ${ }^{7}$. A título de exemplo, percebe-se a perda de referência de tempo [devido aos contratos com prazo determinado que ensejam o seu trabalho]

\footnotetext{
${ }^{6}$ Importa referir que os grupos de sociedades possuem tipologia quanto a sua constituição. Assim, serão qualificados como grupo de base societária quando exista coparticipação societária, com controle societário derivado do instrumento de constituição. Neste caso há que se falar na constituição de um instrumento de concentração empresarial, de natureza jurídica societária. Por outro lado, o grupo de sociedades de base contratual deriva de mera natureza obrigacional, com a constituição dos instrumentos de empresa. Neste caso, o controle, que será extragrupo, deriva de um instrumento contratual de natureza obrigacional, qualificado como negócio jurídico complexo. Para aprofundamento sobre a tipologia dos grupos de sociedades, veja-se: FERRAZ, 2014, p. 494-510; FERRAZ, 2012b, p. $15-25$.

7 Importante observar que, apesar da atividade empresária haver alcançado elevado grau de internacionalização, o mercado de trabalho segue regulado em seu âmbito local, com leis nacionais de proteção do trabalhador, e uma justiça nacional. Assim, depara-se hoje o indivíduo com um mecanismo de proteção sem amplitude para regular a atuação transnacional da atividade empresária e seus efeitos sobre a relação de trabalho. Veja-se, neste sentido: PALAO MORENO, 2000, p. 20 e ss.
} 
DOI:

e espaço [ser possível a prestação de serviços em diversos locais] para o trabalhador terceirizado. Questiona-se, então, o comprometimento da própria subjetividade [trabalhador como sujeito de direitos] nessa modalidade (PAIXÃO; LOURENCO FILHO, 2014, p. 58-74).

\section{TRANSFORMAÇÕES INCONSTITUCIONAIS NO ÂMBITO NACIONAL}

No Brasil, esses temas se encontram na ordem do dia. Deveras, tramita atualmente no Congresso Nacional uma proposta de Reforma da Previdência [PEC 287/2016] e foi aprovada recentemente a Reforma Trabalhista [Lei oㅜ 13.467, de 13 de julho de 2017], que reduzem direitos ${ }^{8}$ dos trabalhadores, ensejando substancial retrocesso social ${ }^{9}$.

À guisa de ilustração, na Reforma da Previdência há o caso paradigmático dos trabalhadores rurais. Após conquistar a igualdade com os trabalhadores urbanos na Constituição Federal (BRASIL, 1988, art. $7^{\circ}$ ) e de receber tratamento previdenciário especial decorrente das peculiaridades de sua atividade (BRASIL, 1988, art. 201, §7, incisos ( e II), a exemplo da dificuldade de registro e a sazonalidade oriunda de períodos de plantio, colheita e safra, a Proposta de Emenda Constitucional 287 põe termo ao regime diferenciado dos trabalhadores rurais, desconsiderando tanto as condições desfavoráveis específicas de trabalho dos camponeses quanto que no contexto social brasileiro, marcado pela desigualdade, essa distinção possui uma

\footnotetext{
${ }^{8}$ Os direitos, sejam de natureza individual, e por isso mesmo privados, sejam de origem coletiva ou erga omnes, possuem custos. Custos estes que deverão ser suportados não só pelo indivíduo, por intermédio de sua esfera patrimonial individual, privada, mas também poderão ser suportados pelo orçamento público, quando se tratarem de direitos coletivos. Os custos da relação de emprego, ainda que suportados, em grande medida pelo empregador, seja público ou privado, geram efeitos para toda a coletividade, já que serão, inclusive, forma de distribuição da riqueza. Para análise dos custos dos direitos, veja-se, de entre muitos: HOLMES; SUNSTEIN, 2011, p. 38 e ss.

9 Importa referir que a redução dos benefícios sociais, ademais das garantias individuais dos trabalhadores, foi incrementada pelo processo de globalização, que ampliou a concorrência entre os agentes econômicos e colocou à descoberto todas as incertezas existentes nos mercados dos países em desenvolvimento. Ademais, questiona, cada dia mais, as certezas dos países desenvolvidos, com suas convicções de proteção do estado do bem-estar social, em especial na UE. Para um aprofundamento sobre a crise da globalização, veja-se: SITGLITZ, 2007, p. 35 e ss. Para uma análise profunda sobre as modificações que a globalização gerou nas relações de trabalho, e no próprio trabalho em si, com alterações de tempo, espaço, especialidade, veja-se: FLORES OLEA; MARIÑA FLORES, 1999, p. 316 e ss.
} 
DOI:

dimensão civilizatória de construção de uma sociedade justa e democrática. A PEC 287 compromete o valor social do trabalho e a dignidade da pessoa humana, fundamentos do Estado Democrático de Direito (PAIXÃO, 2017).

Outrossim, a Reforma Trabalhista contida na Lei ํㅜ 13.467/2017 e a Lei $n^{\circ}$ 13.429/2017, que possibilitou a terceirização irrestrita, constituem grave comprometimento do núcleo axiológico de proteção do trabalho constante na Constituição Federal de 1988. Nesse cenário, houve a ruptura do modelo em que a regra geral apontava para o empregado e o empregador como atores da relação laboral, por meio da contratação direta, ou seja, com o tomador de serviços assinando a carteira de trabalho do empregado. As alterações possuem uma magnitude que, para além de modificarem a forma de organização do trabalho, estabelecem outro paradigma de sociedade, parece ser, incompatível com o texto constitucional (FLEURY; PAIXÃO, 2017) ${ }^{10}$.

O legado deixado pela Assembleia Nacional Constituinte adotou um amplo sistema de proteção dos trabalhadores. Logo em seu art. $1^{\circ}$, IV, a Constituição (BRASIL, 1988) alça os valores sociais do trabalho a um dos fundamentos da República Federativa do Brasil. Em seguida, os arts. 6o a 11 (BRASIL, 1988) qualificam o trabalho como um direito fundamental e arrolam diversos outros direitos de natureza individual e coletiva dos trabalhadores. A manutenção de uma Justiça Especializada [Tribunal Superior do Trabalho, Tribunais Regionais do Trabalho e Juízes do Trabalho, conforme o art. 111 da Constituição Federal (BRASIL, 1988)] também demonstra o compromisso do constituinte com o sistema protetivo do obreiro (LIMA FILHO, 2017, p. 34).

Acrescente-se ainda a instituição do Ministério Público do Trabalho [conforme art. 128, I, b, da Constituição Federal (BRASIL, 1988)] para garantir o cumprimento da legislação trabalhista. A preocupação foi tão significativa com esses direitos que a Carga Magna reservou privativamente à União Federal o poder de legislar sobre matéria trabalhista (BRASIL, 1988, art. 22, I). Do mesmo modo, o constituinte manteve

\footnotetext{
10 Parece ser, ainda, que a modificação do marco regulatório da relação de emprego, com a devida flexibilização da norma, gera efeitos no abandono de aproximação para coesão social que vem sendo travada entre a América Latina e a UE, no sentido da realização da Associação estratégica entre a União Europeia, América Latina e Caribe, que busca harmonização de políticas públicas no âmbito regional. Veja-se, neste sentido: SILVA, K., 2011, p. 53 e ss.
} 
DOI:

reservada na União a competência para realizar, organizar, manter e executar a inspeção do trabalho (BRASIL, 1988, art. 21, XXIV; LIMA FILHO, 2017, p. 34).

No núcleo estruturante do capítulo da ordem econômica, o trabalho também ganhou posição de destaque. Com efeito, o art. 170 da CF (BRASIL, 1988) estabelece a valorização do trabalho humano como um dos fundamentos da ordem econômica. $\mathrm{Na}$ principiologia da Ordem Social, também o trabalho é apontado expressamente como base da organização do sistema (BRASIL, 1988, art. 193). Ademais, há diversos outros dispositivos esparsos no texto constitucional evidenciando a proteção ao trabalho humano. Diante desse arcabouço normativo do trabalho humano, percebese a concepção emancipatória que a Constituição de 1988 atribuiu ao trabalho (LIMA FILHO, 2017, p. 34-35).

Deveras, no ordenamento jurídico pátrio, é possível vislumbrar princípios e dispositivos espalhados que reconhecem os trabalhadores como um dos protagonistas do processo produtivo, alcançando o empoderamento de algumas prerrogativas ${ }^{11}$. Nesse sentido, importante ressaltar inicialmente que os valores da ordem econômica constantes no art. 170 da Constituição Federal (BRASIL, 1988) devem ser interpretados de maneira conjunta. Assim, não há qualquer oposição entre a livre-iniciativa e a justiça social; muito pelo contrário, esses valores se conformam reciprocamente ${ }^{12}$. A função social da empresa ${ }^{13}$ e a justiça social objetivam assegurar a existência digna de todos. Assim, há uma corresponsabilidade entre Estado e indivíduos na construção de uma sociedade mais livre e igual para todos. A livreiniciativa, nessa concepção, revela-se como instrumento da emancipação e exploração das potencialidades de cada ser humano (FRAZÃO, 2014, p. 530).

Nessa linha de entendimento, também a função social dialoga com todos os demais princípios da ordem econômica, sendo certo que a proteção dos trabalhadores consiste em um dos mais relevantes. Por essa razão, como transcrito acima no art.

\footnotetext{
11 Para uma fundamentação teórica, que valoriza a figura do indivíduo em detrimento mesmo da figura do Estado e da Sociedade, veja-se: GOLDMAN, 2008, p. 35 e ss.

12 A liberalização dos mercados foi apresentada aos países em desenvolvimento como a grande panaceia para solução de todos os seus problemas. Contudo, ultrapassada a fase de êxtase, entendeuse da necessidade de regulação dos mercados e de proteção dos mais frágeis na relação jurídica, sejam eles trabalhadores ou consumidores, ou os próprios empresários, que devem viver em condições equilibradas de concorrência. Veja-se, neste sentido: FERRAZ, 2012c, p.11.

${ }^{13}$ Para aprofundar sobre a função social da empresa, veja-se: SERRA, 2010, p.102 e ss.
} 
DOI:

170, III, da CF, há a busca pelo pleno emprego [interpretado sistematicamente não apenas como acesso a um emprego, mas pela oferta das condições socioeconômicas que dão azo à escolha autônoma e com dignidade daquele que atende ao perfil do trabalhador]. Do mesmo modo, o constituinte garantiu aos trabalhadores a participação nos lucros e na cogestão empresarial, conforme a dicção do art. 7ํㅡ, XI (BRASIL, 1988), ainda que a concretização do comando tenha se dado de maneira insuficiente no plano infraconstitucional [tanto no art. $2^{\circ}$ da Lei oㅜ 10.101 (BRASIL, 2000), quanto no parágrafo único do art. 140 da Lei no 6.404 (BRASIL, 1976)]. Não obstante, houve maior avanço no art. $2^{\circ}$ da Lei oㅜ 12.353 (BRASIL, 2010), corroborado pelo art. 19 da Lei o 13.303 (BRASIL, 2016), uma vez que impôs a eleição de representante dos trabalhadores para o Conselho de Administração das Empresas Estatais, Sociedades de Economia Mista, das suas subsidiárias, controladas e demais sociedades empresárias em que a União detiver a maioria do capital social com direito a voto. Inclusive, a responsabilidade social voluntária foi alçada ao plano legislativo, com a autorização de atos gratuitos razoáveis em prol dos empregados, de acordo com o $\S 4^{\circ}$ do art. 154 da Lei oㅜ 6.404 (BRASIL, 1976).

Outro corolário dos princípios constitucionais da ordem econômica se refere à inclusão dos trabalhadores na qualidade de destinatários dos deveres de diligência e lealdade impostos para os administradores de sociedades empresárias ${ }^{14}$. Com efeito, a vedação do abuso de direito, prevista no art. 187 do Código Civil (BRASIL, 2002), já demonstra a necessidade de compatibilização do exercício de um direito com a finalidade para a qual foi atribuído pela sociedade. Assim, os deveres de diligência e lealdade se apresentam como a delimitação do princípio da função social aplicada aos gestores de sociedades empresárias, cabendo indenização na hipótese de descumprimento dos referidos deveres, nos termos do art. 159, $\S 7^{\circ}$, da Lei $n^{\circ}$ 6.404 (BRASIL, 1976). A esse respeito, digno de registro que o art. 116, parágrafo único, do mesmo diploma legal (BRASIL, 1976) evidencia que o poder de controle da companhia deve ser utilizado de forma a proteger também interesses diversos dos acionistas, como os dos trabalhadores, por exemplo (BAPTISTA, 2004, p. 165-201; HOPT, 2008, p. 48-64; TOKARS, 2007, p. 32 e ss). Naturalmente, a necessária

${ }_{14}$ Sobre a responsabilidade dos administradores das sociedades, dentre muitos, veja-se: SILVA, A., 2007, p. 42 e ss. 
DOI:

proteção do trabalho humano deve ocorrer também buscando garantir a preservação da empresa e a rentabilidade dos investidores, uma vez que também são fatores relevantes para o desenvolvimento econômico nacional imprescindível para viabilizar os direitos fundamentais da população (FRAZÃO, 2014, p. 541 e 544-550).

Assim, a política adotada atualmente ao trabalho precisa ser reformulada para se tornar compatível com os valores consagrados na ordem econômica da Constituição de 1988. O trabalho se torna, nesse contexto, elemento central e opera não apenas como meio de subsistência, porém como mecanismo de desenvolvimento da personalidade, integração social e dignidade, alcançando a subjetividade e o patrimônio imaterial do trabalhador (MELLO FILHO; DUTRA, 2014, p. 569). Inadmissível, portanto, o tratamento do trabalho humano como mercadoria e, sobretudo, como valor absolutamente vulnerável às transformações empresariais.

\section{APLICAÇÃO DA TEORIA DA INTEGRIDADE}

Para além da abordagem dogmática, entretanto, a valorização do trabalho humano se mostra necessária para garantir a igual consideração e a autonomia de cada cidadão em determinada comunidade política ${ }^{15}$. Isso porque, a legitimidade de um governo coercitivo requer a obediência a dois princípios fundamentais: demonstrar igual consideração e respeito por cada pessoa sobre a qual possui poder e; respeitar a responsabilidade e o direito individual de escolher como viver. A esse respeito, não seria despiciendo ressaltar que diversos elementos que constituem o acordo político, como a legislação tributária, as políticas fiscal e monetária, as leis trabalhistas, a política de assistência médica etc., interferem diretamente na distribuição da riqueza ${ }^{16}$

\footnotetext{
${ }^{15} \mathrm{O}$ trabalho se qualifica, para Locke, como a necessidade de sobrevivência. Por seu turno, Marx vai além, determinando que o trabalho seria a eterna necessidade imposta pela natureza. Assim, a busca seria a emancipação dos homens quanto à necessidade de trabalho. Emancipação esta que hoje em dia se daria através da tecnologia. Veja-se, neste sentido: ARENDT, 2008, p. 89 e ss.

${ }^{16}$ Para uma análise no sentido de que o Direito, enquanto ciência, seria ineficiente na distribuição da riqueza e que a mesma, se e quando feita, deveria ser praticada pelo Estado, por intermédio de um Sistema de Impostos, veja-se: STORDEUR, 2011, p. 49 e ss. Para uma análise da eficiência das reformas, sob a ótica da Análise Econômica do Direito, veja-se: SPECTOR, 2004, p. 9 e ss. Em sentido contrário, defendendo a possibilidade do Direito, como ciência, assegurar um posicionamento ideológico, defendendo o Estado de bem-estar, veja-se: KENNEDY, 2010, p. 34 e ss; e ainda: CHANG, 2004, p. 176 e ss.
} 
DOI:

e nas oportunidades oferecidas aos cidadãos em cada comunidade (DWORKIN, 2014a, p. 539-540).

No ano de 1996, ocorreu a Reforma da Previdência Social nos Estados Unidos, com evidente retrocesso em matéria de justiça social. A justificativa apresentada para a medida consistiu no excessivo gasto, muito embora não se tenha explicado qual seria o valor que o país deveria despender com os pobres, tornando a afirmação descontextualizada. Com efeito, a construção de um plano distributivo mais justo requer a resposta a uma série de perguntas, como, por exemplo, quem deve fazer jus ao benefício e em que condições, qual o valor aceitável como salário mínimo e quanto se deve gastar com a administração da Previdência (DWORKIN, 2005a, p. 451-453).

Um conhecido exemplo fictício ajuda a elaborar os fundamentos para um plano de previdência dessa natureza. Deveras, em sua abordagem Ronald Dworkin narra um hipotético leilão de seguros em que todas as pessoas recebem a mesma quantidade de recursos, com idêntica possibilidade de contratar um seguro que ofereça certa renda na hipótese de desemprego ou de emprego com salário inferior a essa renda. Com isso, busca-se construir o plano que observe os princípios do igual respeito e consideração por cada pessoa e da autonomia individual pela própria vida. Esse formato não tolhe a liberdade individual, ao mesmo tempo em que permite que as pessoas se protejam dos riscos sociais (DWORKIN, 2005a, p. 81-142 e 467-479).

Sob essa perspectiva, importante salientar que uma interpretação adequada das práticas políticas de uma sociedade leva em consideração a integridade como ideal político diverso ao lado de outras virtudes, como a justiça, a equidade e o devido processo legal. A integridade incide tanto na legislação quanto na deliberação judicial. No primeiro caso, significa que as normas são criadas na tentativa de elaboração de um sistema coerente de justiça e equidade; no segundo, impõe ao magistrado o dever de interpretar o Direito como sendo um conjunto coerente de princípios (DWORKIN, 2014b, p. 259-264).

No âmbito individual, as pessoas devem ser tratadas como membros ativos de uma comunidade. Assim, os sacrifícios impostos para cada cidadão devem ser condicionados à sua efetiva participação no futuro da comunidade, bem como na fruição dos benefícios decorrentes pelas comunidades mais imediatas, como a família. 
DOI:

Por conseguinte, a todas as pessoas deve ser garantido o direito de participar da vida política, econômica e cultural da comunidade. Por exemplo, para uma política econômica que acarrete desemprego, faz-se mister a destinação de recursos significativos para treinamento e empregos públicos. Imprescindível ainda a garantia do acesso à educação para todos e a existência de mobilidade social (DWORKIN, 2005b, p. 315).

Isso porque, o governo tem o dever de tratar os cidadãos com consideração, consubstanciada na compreensão de que são seres humanos sujeitos a sofrimento e frustração, e com respeito, na medida em que as pessoas são suficientemente inteligentes para escolher a melhor forma de condução de suas próprias vidas. Além disso, não bastam respeito e consideração, mas igual respeito e igual consideração, tendo em vista que a vida de todos possui idêntico valor decorrente da qualidade de ser humano. Acrescente-se ainda que dois direitos distintos decorrem desse princípio: 1) o direito ao igual tratamento, isto é, o direito à mesma distribuição de bens $e$ oportunidades que qualquer outra pessoa venha a receber, e; 2) direito a ser tratado como igual, correspondente ao direito de ter sua posição considerada no momento de uma decisão política de distribuição de bens e oportunidades (DWORKIN, 2002, p. 419-420).

Inclusive, a noção de igual respeito e consideração vem sendo utilizada para a densificação do princípio da dignidade da pessoa humana, valor pinacular do ordenamento jurídico pátrio e fundamento contemporâneo da comunidade política. A dignidade humana, nessa concepção, repousa nos atributos de cada ser humano que o faz merecedor de igual respeito e consideração pelo Estado e pela sociedade, impedindo tratamento degradante e garantindo participação nos destinos da própria vida e da sua comunidade política (SARLET, 2004, p. 59-60).

$\mathrm{Na}$ atual quadra, a própria forma do direito se constitui pelos direitos fundamentais de cada cidadão. Não mais se admite, portanto, que o instrumental técnico-jurídico se preste a tentar legitimar um governo arbitrário, uma vez que comprometeria a própria democracia. A compreensão de democracia não se limita aos valores compartilhados pela maioria, devendo assegurar a efetividade dos direitos fundamentais. $O$ embate entre os discursos majoritário e contra-majoritário se mostra imprescindível para a manutenção da reflexividade das posturas ético-políticas e, 
DOI:

consequentemente, para a preservação do potencial emancipatório decorrente (CARVALHO NETTO; SCOTTI, 2011, p. 99-100).

\section{CONCLUSÃO}

Fixados os fundamentos filosóficos, torna-se possível o desenvolvimento de uma política pública que assegure as condições para a efetiva valorização do trabalho humano. Nessa perspectiva, importante levar em consideração, por exemplo, novas reflexões que tomam por base as noções de "agregados contratuais", como fator de organização, troca e consumo na sociedade, e de "nova análise contratual", compreensão que perpassa pela verificação das consequências sociais e econômicas que determinada arquitetura contratual enseja. No aprofundamento dessa concepção, já se percebe a existência de normas jurídicas enviesadas, que atribuem maior poder ao empregador em face do trabalhador (CASTRO, 2014, p. 43-44, 48 e 51).

A rigor, desde a Baixa Idade Média se verifica o fenômeno de completa submissão da empresa aos interesses dos titulares do capital. Ao longo do tempo, constatou-se uma inversão preocupante em um aspecto relevante no processo produtivo: o capital desmaterializou-se, transformando-se em pessoa jurídica, ao passo que os trabalhadores e consumidores passaram a ser tratados como mercadoria. A escravidão constitui exemplo emblemático desse processo, mas não único. Ainda hoje no Brasil, a título de ilustração, os trabalhadores não possuem segurança jurídica adequada. Assim, faz-se mister o desenvolvimento de uma maior coordenação das diversas políticas econômicas e sociais em conjunto com a trabalhista (COMPARATO, 2013, p. 17).

Para além disso, torna-se de fundamental importância ainda a aproximação do Direito Interno Trabalhista com as disposições do Direito Internacional que tratam da temática. Nesse sentido, devem ser considerados irrevogáveis e de eficácia imediata os direitos fundamentais decorrentes das convenções internacionais do trabalho aprovadas pelo Congresso Nacional. Por derradeiro, o Direito do Trabalho interno precisa passar um aperfeiçoamento significativo. Algumas sugestões se referem a um novo regime repressivo para os crimes contra os trabalhadores e à 
DOI:

efetiva participação nos lucros e na gestão da empregadora (COMPARATO, 2013, p. 21-29).

Pelas razões apontadas acima, percebe-se a necessidade de aprofundamento do tema diante da ausência de proteção jurídica do trabalhador em face do novo modelo da empresa fragmentada do século XXI. Isso porque se demonstrou que as transformações empresariais ocorridas nas últimas décadas afastaram a proteção dos trabalhadores, tornando-se necessária a reconstrução dos fundamentos que conferem autonomia para aqueles que oferecem sua força de trabalho no processo produtivo.

Nesse contexto, imprescindível a avaliação se os novos modelos de negócio possuem ou não distinção suficiente em relação aos tradicionais para afastar a proteção dos agentes vulneráveis, como trabalhadores e consumidores. Ademais, não se pode deixar de levar em consideração que mesmo o modelo atual de proteção social dos trabalhadores se mostra insuficiente para garantir a valorização do trabalho humano e a autonomia desses agentes.

Assim, deve ser almejada a construção dos fundamentos para uma política pública trabalhista pautada nos princípios do igual respeito e consideração e da autonomia de cada cidadão. As relações de produção precisam ser revisitadas de modo a garantir a emancipação do trabalhador, que passa a exercer suas funções não como mercadoria ou como meio de subsistência, mas como sujeito que oferece para a sociedade suas potencialidades enquanto manifestação da sua dignidade no mundo do trabalho.

Com esse desiderato, apresenta-se como adequada a teoria da integridade desenvolvida por Ronald Dworkin, tendo em vista que busca a construção de um sistema moralmente coerente, com base em normas de um sistema caracterizado pela justiça e equidade. A integridade deve ser adotada tanto sob a perspectiva da política, densificando de forma reflexiva um complexo de princípios morais comungados por uma comunidade, quanto no viés do Direito, de maneira que a interpretação jurídica deve garantir segurança jurídica e justiça. 
DOI:

\section{REFERÊNCIAS}

AMATORI, Franco; COLLI, Andrea. Storia d'impresa: Complessità e comparazione. Milão: Pearson Italia, 2011.

ANTUNES, José A. Engrácia. Estrutura e Responsabilidade da Empresa: o moderno paradoxo regulatório. Revista Direito GV 2, São Paulo, v. 1, n. 2, p. 29-68, jun./dez. 2005.

ARAÚJO, Fernando. Teoria económica do contrato. Coimbra: Almedina, 2007.

ARENDT, Hannah. Labor, Trabajo, Acción. In: De la historia a la acción. Barcelona: Ediciones Paidós, 2008.

BAPTISTA, Ezio Carlos S. Administradores de sociedades limitadas. In: ALMEIDA, Marcus Elidius Michelli de (Coord.). Aspectos jurídicos da sociedade limitada. São Paulo: QuartierLatin, 2004.

BARBIER, Eduardo Antonio. Contratación bancaria. Buenos Aires: Astrea, 2007.

BRASIL. Constituição da República Federativa do Brasil de 1988. Disponível em:< http://www.planalto.gov.br/ccivil_03/constituicao/constituicao.htm>

Lei 6.404, de 15 de dezembro de 1976. Dispõe sobre as Sociedades por Ações. Disponível em: < http://www.planalto.gov.br/ccivil_03/leis/L6404consol.htm>.

Lei 10.101, de 19 de dezembro de 2000. Dispõe sobre a participação dos trabalhadores nos lucros ou resultados da empresa e dá outras providências. Disponível em: < http://www.planalto.gov.br/ccivil_03/leis/L10101.htm>.

. Lei 10.406, de 10 de janeiro de 2002. Institui o Código Civil. Disponível em: <http://www.planalto.gov.br/ccivil_03/leis/2002/L10406.htm>.

Lei 12.353, de 28 de dezembro de 2010. Dispõe sobre a participação de empregados nos conselhos de administração das empresas públicas e sociedades de economia mista, suas subsidiárias e controladas e demais empresas em que a União, direta ou indiretamente, detenha a maioria do capital social com direito a voto e dá outras providências. Disponível em: < http://www.planalto.gov.br/ccivil_03/_ato20072010/2010/lei/l12353.htm>.

. Lei 13.303, de 30 de junho de 2016. Dispõe sobre o estatuto jurídico da empresa pública, da sociedade de economia mista e de suas subsidiárias, no âmbito da União, dos Estados, do Distrito Federal e dos Municípios. Disponível em: < http://www.planalto.gov.br/ccivil_03/_ato2015-2018/2016/lei//13303.htm>.

CARVALHO NETTO, Menelick de; SCOTTI, Guilherme. Os Direitos Fundamentais e a (In)Certeza do Direito? A Produtividade das Tensões Principiológicas e a Superação do Sistema de Regras. 1. ed. Belo Horizonte: Editora Fórum, 2011. v. 1. 
DOI:

CASTELLS, Manuel. A sociedade em rede. Tradução de Roneide Venancio Majer com a colaboração de Klauss Brandini Gerhardt. 2. ed. São Paulo: Paz e Terra, 1999.

CASTRO, Marcus Faro de. Novas Perspectivas Jurídicas sobre a Reforma de Políticas Públicas no Brasil. Revista de Direito da Universidade de Brasília, Brasília, v. 1, p. 32-64, 2014.

CHANG, Há-Joon. Retirar la escalera - la estrategia del desarrollo en perspectiva histórica, Madrid: Instituto Complutense de Estudios Internacionales, 2004.

COMPARATO, Fábio Konder. A proteção do trabalho assalariado no Brasil. Revista TST, Brasília, v. 79, n. 3, jul./set. 2013.

DWORKIN, Ronald. Levando os direitos a sério. Tradução: Nelson Boeira. São Paulo: Martins Fontes, 2002.

. Uma questão de princípio. Tradução: Luís Carlos Borges. 2. ed. São Paulo: Martins Fontes, 2005. p. 315.

A virtude soberana: a teoria e a prática da igualdade. Tradução: Jussara Simões. São Paulo: Martins Fontes, 2005. p. 451-453 e p. 81-142 e 467-479.

. O império do direito. Tradução: Jefferson Luiz Camargo. 3. ed. São Paulo: Martins Fontes, 2014. p. 259-264.

A raposa e o porco-espinho: justiça e valor. Tradução: Marcelo Brandão Cipolla. São Paulo: WMF Martins Fontes, 2014. p. 539-540.

FERRAZ, Daniel Amin. Acordos horizontais, acordos verticais e a jurisprudência norteamericana e europeia sobre a matéria. Revista de Direito Internacional, Brasília, v. 9, n. 2, p. 149-160, jul./dez. 2012.

. Da qualificação jurídica das distintas formas de prestação tecnológica: breve análise do marco regulatório internacional. Revista de Direito Internacional, Brasília, v. 12, n. 2, p. 449 e ss., 2015.

. Grupo de sociedades: instrumento jurídico de organização da empresa plurissocietária. Revista de Direito Internacional, Brasília, v. 12, n. 2, p. 494-510, 2014.

2001

. Joint ventures e contratos internacionais. Belo Horizonte: Mandamentos,

O grupo de sociedades: mecanismo de inserção da empresa transnacional na nova ordem econômica internacional. Revista de Direito Internacional, Brasília, v. 9, n. 1, p. 15-25, jan./jun. 2012. 
DOI:

Direito Empresarial: marco jurídico de internacionalização das empresas brasileiras. Curitiba: Editora CRV, 2012. p. 11.

FERRAZ, Daniel Amin; SÁ, Marcus Vinicius Silveira de. Da desconsideração da personalidade jurídica nas relações consumeristas brasileiras: análise à luz das teorias clássicas. Revista de Direito Internacional, Brasília, v. 13, n. 3, p. 306-317, 2016.

. Da teoria objetiva da desconsideração da personalidade jurídica e os grupos de sociedades sob a ótica das relações de consumo. Revista Brasileira de Políticas Públicas, Brasília, v. 6, n. 3, p. 120-139, 2016.

FLEURY, Ronaldo Curado; PAIXÃO, Cristiano. Reforma Trabalhista: Terceirização contra a Constituição. Tema da terceirização não é apenas uma discussão sobre formas de prestação do trabalho. Portal Jota. Coluna Democracia e Sociedade, de 27 abr. 2017. Disponível em: <https://jota.info/colunas/democracia-esociedade/reforma-trabalhista-terceirizacao-contra-a-constituicao-27042017> Acesso em: 18 jun. 2017.

FLORES OLEA, Víctor; MARIÑA FLORES, Abelardo. Crítica de la globalidade. México - DF: Fondo de Cultura Económico, 1999.

FONT GALÁN, Juan Ignacio. La empresa en el Derecho Mercantil. In: JIMÉNEZ SANCHEZ, Guillermo J. Derecho Mercantil I. Barcelona: Marcial Pons, 2010. v. 1

FRAZÃO, Ana. A ordem econômica constitucional e os contornos da proteção do trabalhador. In: FRAZÃO, Ana; SARLET, Ingo; VIEIRA DE MELLO, Luiz Philippe. (Org.). Diálogos entre o Direito do Trabalho e o Direito Constitucional. 1. ed. São Paulo: Saraiva, 2014, v. 1. p. 529-552.

. Joint ventures contratuais. Revista de informação legislativa, v. 52, n. 207 , p. 187-211, jul./set. $2015 . \quad$ Disponível em: <http://www2.senado.leg.br/bdsf/handle/id/515194>. Acesso em: 15 jun. 2017.

Networks e redes contratuais: Desafios da crescente sofisticação e interdependência funcional entre contratos empresariais. Portal Jota. Coluna Constituição, Empresa e Mercado, de 04 mai. 2017. Disponível em: $<$ https://jota.info/colunas/constituicao-empresa-e-mercado/networks-e-redescontratuais-04052017>. Acesso em: 17 jun. 2017.

Networks e redes contratuais II: As dificuldades de compreensão das fronteiras cada vez mais tênues da empresa. Portal Jota. Coluna Constituição, Empresa e Mercado, de 31 mai. 2017. Disponível em: $<$ https://jota.info/colunas/constituicao-empresa-e-mercado/networks-e-redescontratuais-ii-31052017>. Acesso em: 17 jun. 2017.

Economia do compartilhamento e tecnologias disruptivas: A compreensão dos referidos fenômenos e suas consequências sobre a regulação jurídica. Portal 
DOI:

Jota. Coluna Constituição, Empresa e Mercado, de 14 jun. 2017. Disponível em: <https://jota.info/colunas/constituicao-empresa-e-mercado/economia-docompartilhamento-e-tecnologias-disruptivas-14062017>. Acesso em: 17 jun. 2017.

GOLDMAN, Emma. La palabra como arma. Islas Canarias-Madrid: Tierra de FuegoLa Malatesta Editorial, 2008.

HOLMES, Stephen; SUNSTEIN, Cass R. El costo de los derechos - por qué la libertad depende de los impuestos. Buenos Aires: Siglo Veintiuno, 2011.

HOPT, Klaus. Modernização do direito societário: perspectiva transatlântica. Revista Direito GV, São Paulo, v. 4, n. 1, jan-jun/2008.

KENNEDY, Duncan. Izquierda y derecho - Ensayos de teoría jurídica crítica. Buenos Aires: Siglo Veintiuno, 2010.

LIMA FILHO, Gerardo Alves. 10 razões para tornar inconstitucional a lei da terceirização irrestrita. Revista Conceito Jurídico: Trabalhista, Sindical e Previdenciário, Ano I, n. 2, p. 33-39, fev. 2017. ZK Editora. Enfoque.

MELLO FILHO, Luiz Philippe Vieira de; DUTRA, Renata Queiroz. Centralidade da pessoa humana na Constituição versus centralidade do cidadão trabalhador: o desafio de reler o trabalho a partir da Constituição Federal de 1988. In: FRAZÃO, Ana; SARLET, Ingo; VIEIRA DE MELLO, Luiz Philippe. (Org.). Diálogos entre o Direito do Trabalho e o Direito Constitucional. São Paulo: Saraiva, 2014, v. 1.

PAIXÃO, Cristiano; LOURENCO FILHO, R.. Impactos da terceirização no mundo do trabalho: tempo, espaço e subjetividade. Revista do Tribunal Superior do Trabalho, v. 80, p. $58-74,2014$.

A Reforma da Exclusão: trabalhadores rurais e PEC 287. Análise sobre a Reforma da Previdência. Portal Jota. Coluna Democracia e Sociedade, de 31 mar 2017. Disponível em: <https://jota.info/colunas/democracia-e-sociedade/a-reformada-exclusao-trabalhadores-rurais-e-pec-287-31032017>. Acesso em: 18 jun. 2017.

PALAO MORENO, Guillermo. Los grupos de empresas multinacionales y el contrato individual de trabajo. València: Tirant lo Blanc, 2000.

RIZZARDO, Arnaldo. Contratos de crédito bancário. 7. ed. São Paulo: Editora Revista dos Tribunais, 2007.

SARLET, Ingo Wolfgang. Dignidade da pessoa humana e direitos fundamentais na Constituição Federal de 1988. 3. ed. Porto Alegre: Livraria do Advogado, 2004.

SERRA, Catarina. O novo Direito das Sociedades: para uma governação socialmente responsável. Scientia luris, Londrina, v. 14, p.102 e ss., nov. 2010. 
DOI:

SILVA, Alexandre Couto. Responsabilidade dos administradores de S/A. Rio de Janeiro: Elsevier, 2007.

SILVA, Karine de Souza. Los intereses involucrados en la promoción de la cohesión social por la asociación estratégica entre la Unión Europea, Latinoamérica y el Caribe. In: THEILER, Julio Cesar; MAÍZ, Claudio; AGRAMUNT, Luis Felipe. Los desafios de la integración en el siglo XXI. Santa Fe: Ediciones UNL, 2011.

SITGLITZ, Joseph E. El malestar en la globalización. Madrid: Santillana Ediciones, 2007.

SPECTOR, Horacio. Elementos de análisis económico del Derecho. Buenos Aires: Rubinzal-Culzoni Editores, 2004.

STORDEUR, Eduardo. Análisis Económico del Derecho. Buenos Aires: Abeledo Perrot, 2011.

TOKARS, Fábio. Sociedades limitadas. São Paulo: LTr, 2007. 